\title{
Numerical simulation of failure process of rock mass with a joint
}

\author{
Fengshan $\mathrm{Han}^{1, \mathrm{a}}$, Xinli $\mathrm{Wu}^{2 \mathrm{~b}}$ \\ ${ }^{1}$ Research Center for Numerical Tests on Material Failure, Dalian University, Dalian, 116622, China \\ ${ }^{2}$ Colleague of Engineering, the Pennsylvania State University, Pennsylvania, USA \\ ahanfs@sohu.com bxinli@psu.edu \\ Corresponding author: hanfs@sohu.com
}

Keywords: Natural joint, rock mass, failure process, numerical simulation

\begin{abstract}
In this paper failure process of rock mass with a natural joint is presented by numerical simulation based on RFPA $^{2 \mathrm{D}}$. numerical simulation shown that failure of rock mass with a natural joint begin first in joint for rock mass, with the increase of the vertical load, joint is closed, along the joint plane within the rock mass near the damage area, rock mass became damaged gradually near joint, the damage area expands unceasingly, then cave is formed. That provided location and avenue for movement and accumulation of underground water. That is of significance and valuable to research strength for jointed rock mass and to research mechanism of propagation and coalescence and evolvement of joints in rock mass and to research mechanism of mine water and gas outburst in underground mining and to research catastrophe and bifurcation of non Darcy flow system in post failure of rock mass. Numerical simulation shown that when angle between the joint plane and horizontal plane is $30^{\circ}$, and when the lateral pressure is $1 \mathrm{Mpa}$, compressive strength of rock mass with a natural joint is compressive strength of $25.9 \%$ without joint.
\end{abstract}

\section{Introduction}

In the study of rock mass mechanics, crack propagation and the polymerization is an important content in the research of rock fracture mechanics. It is difficult to research the failure process for rock mass with natural joint under the load condition by analytical method. With the development of numerical simulation technology, Using numerical simulation method to study contains natural joint rock fracture process under outside load has become possible. RFPA, rock failure process analysis system provides the economy method to research rupture process containing natural joint rock. To research failure process containing natural joint rock under the influence of outer load, for revealing aggregation and transfixion and evolution mechanism under the influence of outer load extension, to research groundwater migration and enrichment regularity, the mine water inrush hazard mechanism, has the research significance and application value.

\section{Numerical Model}

In order to simulate the natural joint rock failure process, the mesh elements used for this modeling is $100 \times 100$ in elements with a geometry of $100 \mathrm{~mm} \times 100 \mathrm{~mm} \times 100 \mathrm{~mm}$ in size, as shown in Fig. 1 and the simulated rock sample for sandstone is with a geometry of $100 \mathrm{~mm} \times 100 \mathrm{~mm} \times 100 \mathrm{~mm}$ in size, all the elements have the same size, the mechanical parameters, such as strength and elastic modulus of element, according to the statistical strength theory obeys weibull distribution

$$
\Phi(x)=\frac{m}{x_{0}}\left(\frac{x}{x_{0}}\right)^{m-1} e^{-\left(\frac{x}{x_{0}}\right)^{m}}
$$

\section{Numerical simulation model and mechanical parameters}

Numerical simulation model is divided into $100 \times 100$ units, to simulate the large size $100 \mathrm{~mm} \times 100 \mathrm{~mm} \times 100 \mathrm{~mm}$ cube contains natural joint sandstone samples. joint plane and horizontal 
plane angle is 30 degrees. As shown in figure 1. Numerical simulation model of the sandstone rock mechanics parameters are shown in Table 1, the numerical model of the joint mechanical parameters are shown in Table 2.

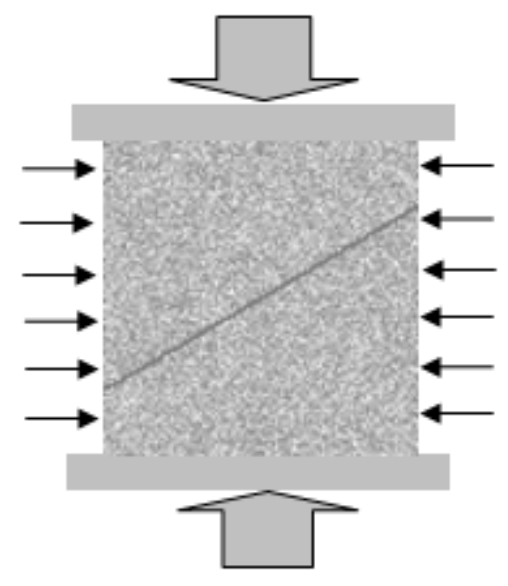

Fig.1 Numerical simulation model containing natural joints for large size sandstone

Table 1.Parameters of numerical simulation for sandstone

\begin{tabular}{lc}
\hline Homogeneneity index, m & 3 \\
Mean elastic modulus, $E_{\circ}$, Gpa & 20 \\
Average compressive strength of elements for rock $\sigma_{o}$, Mpa 80 \\
Internal friction angle, $\phi^{\circ}$ & 30 \\
Poisson's ratio, $\mu$ & 0.25 \\
Ratio of compressive to tensile strength, C/T & 10 \\
Confining pressure, Mpa & 1 \\
\end{tabular}

Table 2. Parameters of numerical simulation for natural joint

\begin{tabular}{lc}
\hline Homogeneneity index, m & 3 \\
Mean elastic modulus, $E_{\circ}, \mathrm{Mpa}$ & 1 \\
Average compressive strength of elements for rock $\sigma_{o}, \mathrm{Mpa} 0.1$ \\
Internal friction angle, $\phi^{\circ}$ & 30 \\
Poisson's ratio, $\mu$ & 0.25 \\
Ratio of compressive to tensile strength, C/T & 10 \\
\hline
\end{tabular}

\section{Boundary conditions and loading method for Numerical simulation}

Numerical simulation model for lateral pressure is $1 \mathrm{Mpa}$, axial pressure load by displacement control, the initial value of axial load displacement is $0.001 \mathrm{~mm}$, axial load displacement increment is $0.1 \mathrm{~mm} /$ each step, the total number of numerical simulation is 700 steps. 


\section{Numerical results}

Based on RFPA ${ }^{2 D}$,Numerical simulation of failure process containing natural joint sandstone joint rock is shown in figure 2. numerical simulation of failure process of no joint sandstone cube sample under lateral pressure $1 \mathrm{Mpa}$ is shown in figure 3. Numerical results shown that contains a single natural joint sandstone cube sample when the lateral pressure is $1 \mathrm{Mpa}$, peak load Nmax $=6555 \mathrm{~N}$. Therefore contains a single natural joint sandstone cube sample when the lateral pressure is $1 \mathrm{Mpa}$, Compressive strength of rock mass is $6.555 \mathrm{Mpa}$, However, without joint sandstone cube sample when the lateral pressure is $1 \mathrm{Mpa}$, Compressive strength of rock mass is $25.276 \mathrm{Mpa}$

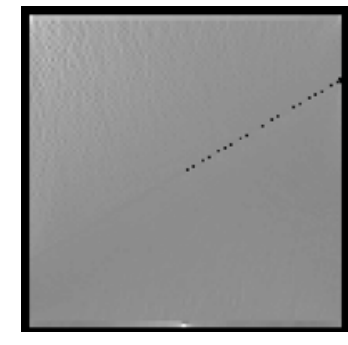

Step 2

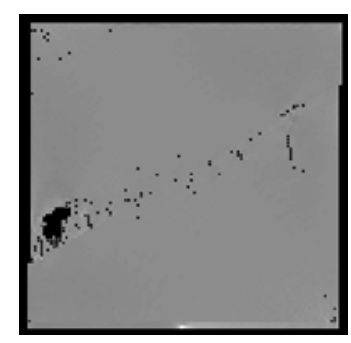

Step 249

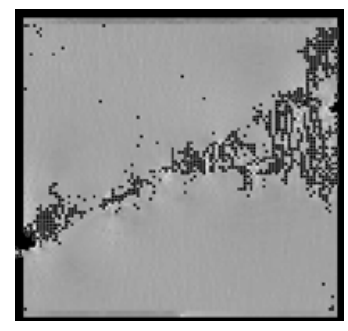

Step 600

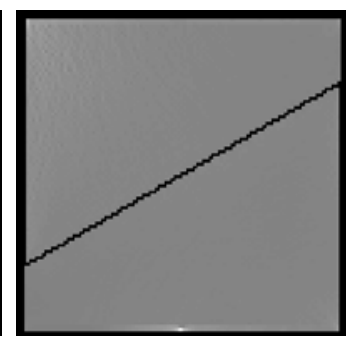

Step 4

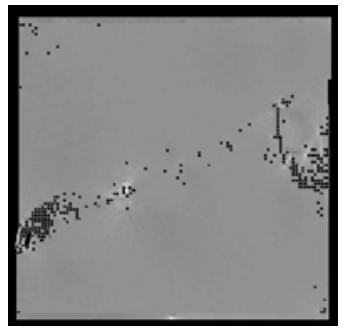

Step 328

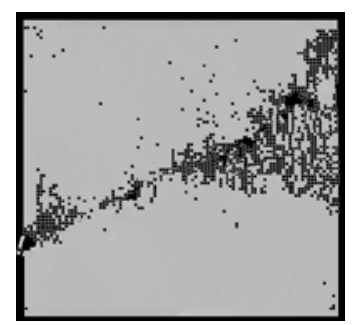

Step 623

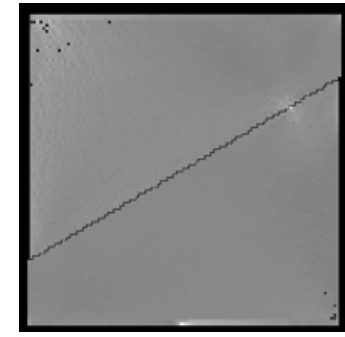

Step 80

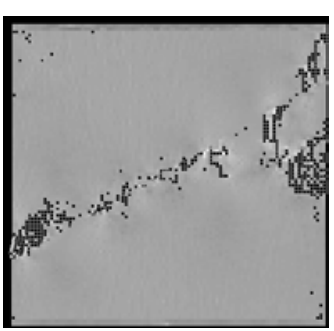

Step 462

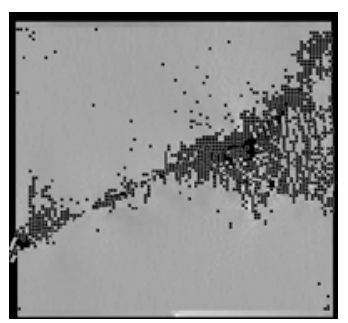

Step 637

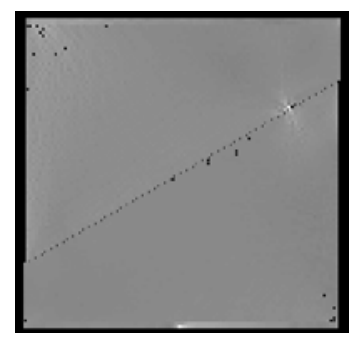

Step 125

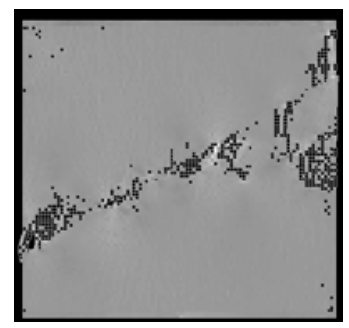

Step 500

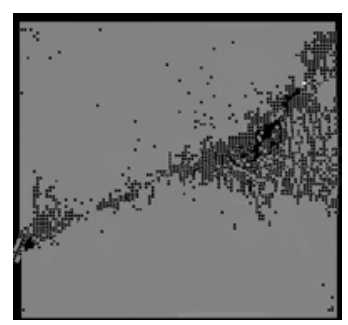

Step 650

Fig 2. Failure process of compressive experiment of rock mass with a natural joint by numerical simulation. 


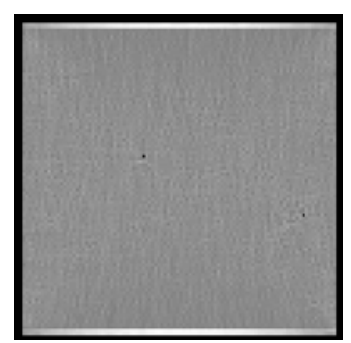

Step 14

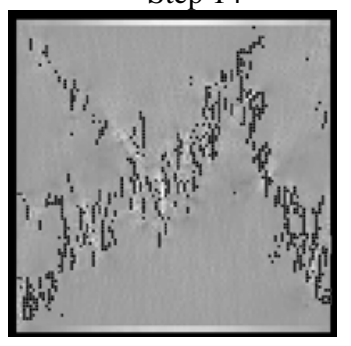

Step 45

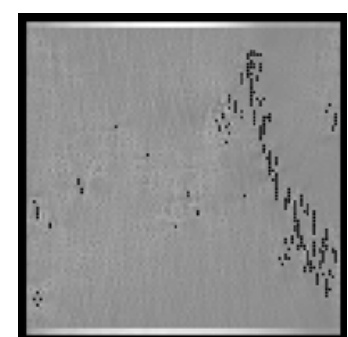

Step 17

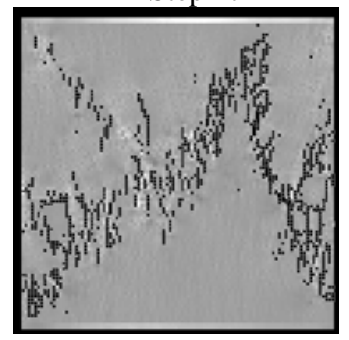

Step 71

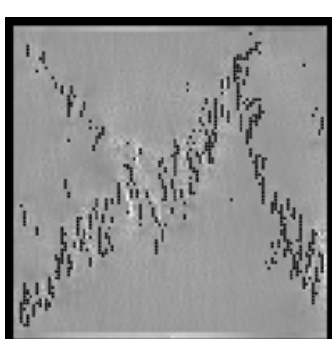

Step 19

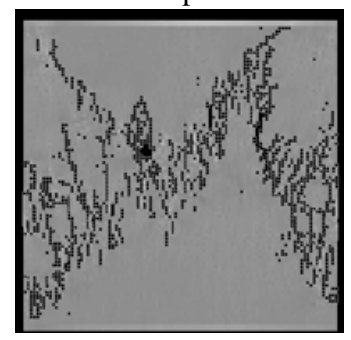

Step 100

Fig 3.The Failure process for sandstone without joint for numerical simulation

\section{Conclusions}

In this paper failure process of rock containing a natural joint by numerical simulation, the following preliminary conclusions can be obtained:

1. With a single natural joint, joint plane and horizontal plane Angle of 30 degrees, containing a single joint rock compressive strength is no joint rock compressive strength of $25.9 \%$.

2. Contains natural joint rock failure process from the results of numerical simulation can be seen that the joint rock burst, starting from the joint rock mass, cracking along the joint part, first, the rock mass along the joint plane all through. Along with the increase of the vertical load of the rock mass, joint was closed. Along the joint plane, the rock mass within the rock mass near the damage area. With the increase of the vertical load, the damage area expands unceasingly, along the joint plane of rock mass near formation connected channels and hollow. For the occurrence of groundwater, gather and provide the places and ways, also affected by mining, for research on joint rock peak after the non-Dacy seepage mutation and bifurcation, provides the basis of a visual image which is significance to understand the performance of the rock in deep underground.

\section{Acknowledgements}

This research is funded by the "Project of science and technical program of the Educational Department of Liaoning Province (L2012436) " and "Open Projects of State Key Laboratory of Coal Resources and Safe Mining of China University of Ming and Technology (11KF07)”

\section{References}

[1] C.A.Tang, Numerical simulation of progressive rock falure and associated seismicity. Int J Rock Mech Min Sci[J] 1997.34(2):249-261

[2]C.A.Tang, S.Q.Kou, Crack propagation and coalescence in brittle material under compression, Engineering Fracture Mechanics [J]. 1998.61:311-324

[3] E.Hoek, E.T.Brown, Underground excavation in rock[M], London, 1980.

[4] C.A.Tang, Numerical test on micro-macro relationship of rock failure under uniaxial compresion ,part I: effect of heterogeneneity, Int J Rock Mech Min Sci[J],2000, 37: 555-569 
[5] C.A.Tang,.B.Zhang,Z.Z.Liang,T.Xu,L.G.Tham,P_A.Lindqvist,S.Q.Kou,H.Y.Liu,Fracture spacing in layered materials and polygonal fracture, Physical Review E [J], 2006, 73(3): 70-83 